\title{
Observational study on the utilization pattern of adjuvant anti-epileptics and their adverse effects
}

\author{
Punitha Rangarajan $^{1}$, Kulandaiammal Moorthy ${ }^{1}$, Arunan Subbiah ${ }^{2}$
}

\author{
${ }^{1}$ Department of Pharmacology, ${ }^{2}$ Department of Neurology, Govt. Stanley Medical College, Chennai, Tamil Nadu, \\ India
}

Received: 30 October 2019

Accepted: 06 December 2019

\section{*Correspondence:}

Dr. Kulandaiammal Moorthy,

Email: drkulandpharma@gmail.com

Copyright: (c) the author(s), publisher and licensee Medip Academy. This is an open-access article distributed under the terms of the Creative Commons Attribution Non-Commercial License, which permits unrestricted non-commercial use, distribution, and reproduction in any medium, provided the original work is properly cited.

\begin{abstract}
Background: Epilepsy is a disease characterized by an enduring predisposition to generate epileptic seizures. Pharmacological therapy is the cornerstone of treatment of epilepsy. In more than $50 \%$ patients seizure not controlled with first-line anti-epileptic drugs so added with adjuvant drugs. Therefore adjuvant anti-epileptic drugs play an important role in preventing seizure remission in known epilepsy patients. Observational study was to evaluate the utilisation pattern of adjuvant anti-epileptic drugs and to assess their clinical correlation and observe the adverse effects of the adjuvant anti-epileptics.

Methods: Eligible 100 patients who attended the neurology outpatient department where enrolled in the study. Demographic data, type of epilepsy, presence or absence of seizure episode (4 months), adjuvant anti-epileptic prescribed along with the first-line drugs and adverse effects were noted. Clinical correlation and rationale for the usage of adjuvant anti-epileptics were assessed. Descriptive statistics used for statistical analysis.

Results: The most common types of seizures were generalised tonic clonic seizures (41\%) and complex partial seizures $(37 \%)$. Most commonly used $1^{\text {st }}$ line drug was phenytoin tablet. Most common adjuvant anti-epileptics used were clonazepam (30), clobazam (24) tablets. Most common adverse effect noted was dizziness (31\%).

Conclusions: Tablet clonazepam is effective adjunct for tonic clonic seizures. Clobazam table is recommended as add-on drug for focal and generalised seizures. Adjuvant anti-epileptic drugs decrease seizure remission with fewer tolerable adverse effects.
\end{abstract}

Keywords: Epilepsy, Seizure, Anti-epileptic, Adjuvant, Adverse effects

\section{INTRODUCTION}

Epilepsy is one of the most common serious neurological conditions characterised by recurrent seizures. Abnormal excessive hyper synchronous electrical activity of brain marks a seizure episode. International league against epilepsy (ILAE) defines epilepsy as disease with at least two unprovoked seizures $>24$ hours apart or one unprovoked seizure with recurrence risk or an epilepsy syndrome. ${ }^{1}$
There are about 50 million people affected by epilepsy worldwide. Among them 10 million belong to India (about $1 / 5^{\text {th }}$ ). ${ }^{2}$ The disease burden of epilepsy in India accounts for $1 \%$ of total burden of world. Seizures can be classified as generalized, partial and unknown onset which includes tonic-clonic, atonic and epileptic spasms. ${ }^{3}$ The manifestations of seizure depend on the area of brain from where it arises. Clonic jerky movements occur with motor cortex involvement. Generalized seizure is subdivided into tonic-clonic, absence or myoclonic. Partial seizures can be associated with loss of 
consciousness or preserved consciousness. It can evolve to tonic-clonic seizure (sustained contraction, followed by alternate phases of contraction and relaxation of muscles).

Pharmacological therapy is the cornerstone of treatment of Epilepsy. The ideal anti-epileptic drug (AED) would suppress all seizures without causing any unwanted effects. Patient is started with single first - line AED as monotherapy, if seizure not controlled adjuvant Anti epileptic drugs are added. ${ }^{3}$ Drugs with different mechanisms are usually combined. The investigations done routinely are electroencephalogram (EEG) and magnetic resonance imaging (MRI). The commonly used First-line drugs are sodium valproate for generalized seizures and carbamazepine for partial seizures. ${ }^{4}$ The conventionally used adjuvant drugs are clobazam, levetiracetam, oxcarbazepine, topiramate, zonisamide, lamotrigine, gabapentin, pregabalin, vigabatrin, tiagabine and eslicarbazepine. ${ }^{5}$ In $30-53 \%$ patients, seizure control could not be achieved with monotherapy alone.

Adjuvant anti-epileptic drugs play a very important role in the control of seizures along with first line drugs. Previous studies done on drug utilization pattern of all anti-epileptic drugs. ${ }^{6}$ This study is done to evaluate the utilization pattern and adverse effects of adjuvant antiepileptics thereby to assess the clinical correlation of their usage and highlights the importance of adjuvant antiepileptics.

\section{METHODS}

The study was started after getting Institutional Ethics Committee approval. The study was designed in accordance with the ethical standards laid down by ICMR Ethical Guidelines for Biomedical Research on Human Subjects. It is a single centre, prospective, observational study of 4 months duration (March 2018 to June 2018). Subjects were selected from patients attending neurology outpatient department in Govt. Stanley medical college, Chennai, Tamil Nadu.

\section{Inclusion criteria}

Patients who are known case of Epilepsy started on combination anti-epileptic drugs; patients of age 18-70 years; patients of either sex; patients who are willing to give informed consent were included in this study.

\section{Exclusion criteria}

Patients less than 18 years and more than 70 years; patients on monotherapy of anti-epileptic drug; patients presenting with status epilepticus; epilepsy due to other causes like infective, metabolic, genetic and structural etiology; pregnant and lactating women were excluded in this study.

\section{Study procedure}

Among 112 patients screened totally, eligible 100 patients who attended the neurology outpatient department were enrolled to the observational study on the utilisation pattern of adjuvant anti-epileptic drugs. The patients were given all information about the study in regional language and obtained written informed consent. The demographic data (age, sex), prescription details (diagnosis, drug details- dose, frequency of first-line and adjuvant AEDs), presence or absence of seizure (4 months) and adverse effects were noted from the patients.

\section{Statistical analysis}

All data collected were entered in Microsoft excel worksheet (version - 2007). Data were analyzed using Graph pad prism software, version 7.04. Case report forms were used to enter demographic data, diagnosis and details of drugs prescribed. Adverse effects were noted as reported by patients.

\section{RESULTS}

112 patients who attended the neurology outpatient department were screened for selection of participants to the study. 12 were excluded since they didn't meet the inclusion criteria.100 patients were included in the study. Among 100 patients, the types of seizures (Figure 1) noted were generalised tonic clonic seizures (41\%), complex partial seizures (37\%), secondary generalized seizures (12\%) and simple partial seizures (10\%).

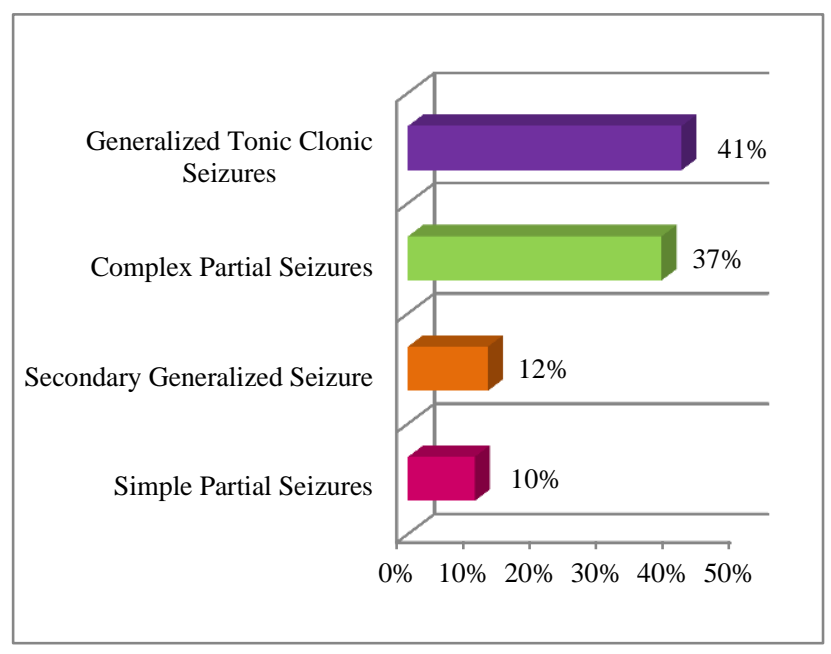

Figure 1: Types of seizures.

Among 100 patients, $43 \%$ patients belong to age group 21-30 years, $30 \%$ belong to $31-40$ years age group. $41-50$ years-10\%, 51-60 years: $12 \%, 61-70$ years: $5 \%$ as illustrated in Figure 2. Sex distribution illustrated in Figure 3 reveals male predominance $(61 \%)$ and $49 \%$ were female. 


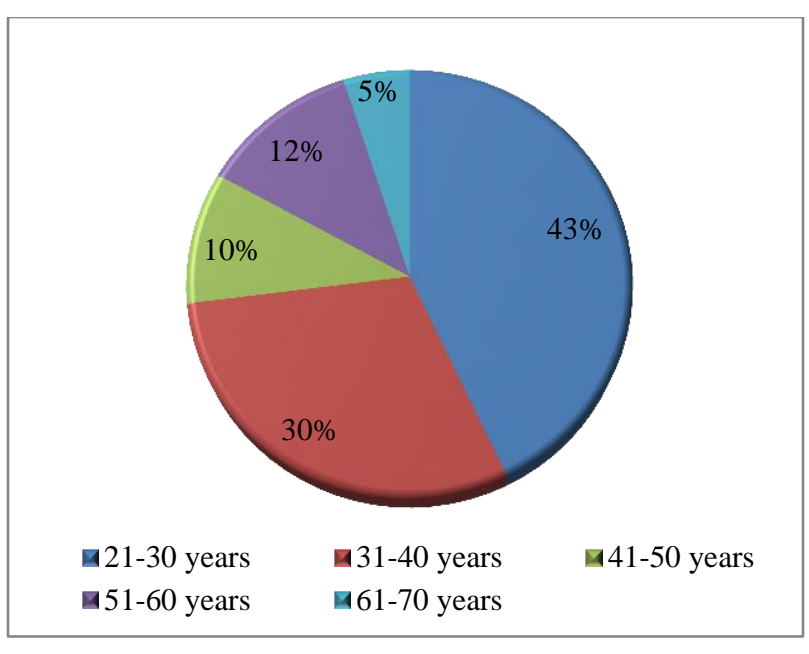

Figure 2: Age distribution.

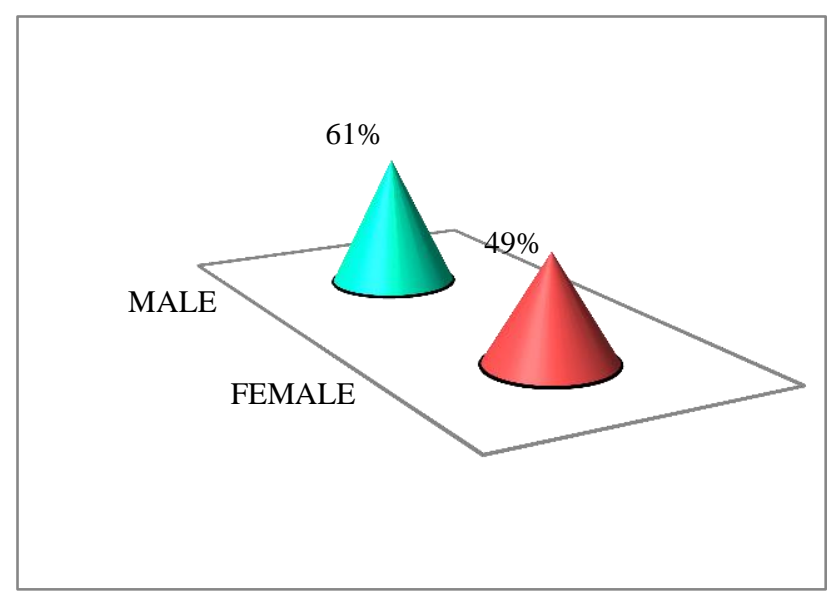

Figure 3: Sex distribution.

The following first-line anti-epileptic drugs were prescribed phenytoin (45\%), sodium valproate $(30 \%)$, carbamazepine $(24 \%)$ and phenobarbitone $(1 \%)$ tablets. The adjuvant anti-epileptic drugs prescribed were clonazepam, clobazam, levetiracetam, gabapentin, lamotrigine, topiramate and pregabalin tablets as indicated in Table 1.

Table 1: Summary of adjuvant anti-epileptics (n=96) .

\begin{tabular}{|lll|}
\hline Adjuvant drug & $\begin{array}{l}\text { No of times } \\
\text { prescribed }\end{array}$ & $\%$ \\
\hline Clonazepam tablet $\mathbf{0 . 5} \mathbf{~ m g}$ & 40 & 41.67 \\
\hline Clobazam tablet $\mathbf{5} \mathbf{~ m g}$ & 32 & 33.33 \\
\hline Levetiracetam tablet $\mathbf{2 5 0} \mathbf{~ m g}$ & 10 & 10.42 \\
\hline Gabapentin tablet $\mathbf{3 0 0} \mathbf{~ m g}$ & 6 & 6.25 \\
\hline Lamotrigine tablet $\mathbf{2 5} \mathbf{~ m g}$ & 5 & 5.21 \\
\hline Pregabalin tablet $\mathbf{7 5} \mathbf{~ m g}$ & 2 & 2.08 \\
\hline Topiramate tablet $\mathbf{5 0} \mathbf{~ m g}$ & 1 & 1.04 \\
\hline
\end{tabular}

The patients, who were started on adjuvant anti-epileptics, were monitored for frequency of seizure episodes for 4 months period. Among the 100 patients, 60 patients were on one first line and one adjuvant drug, 26 patients were on two first line drugs and one adjuvant drug, 9 patients were on only two first line drugs alone and 5 patients were on one first line and two adjuvant drugs. The percentage of seizure free patients depicted in Table 2 .

Table 2: Details of seizure free patients $(n=100)$.

\begin{tabular}{|llll|}
\hline $\begin{array}{l}\text { Anti-epileptic } \\
\text { drugs }\end{array}$ & $\begin{array}{l}\text { No of } \\
\text { patients }\end{array}$ & $\begin{array}{l}\text { Seizure } \\
\text { free }\end{array}$ & $\%$ \\
\hline $\begin{array}{l}\text { First line+ } \\
\text { adjuvant }\end{array}$ & 60 & 43 & 71 \\
\hline $\begin{array}{l}\text { First line+2nd first } \\
\text { line+adjuvant }\end{array}$ & 26 & 11 & 42 \\
\hline $\begin{array}{l}\text { First line+1st } \\
\text { adjuvant+2nd } \\
\text { adjuvant }\end{array}$ & 5 & 4 & 80 \\
\hline $\begin{array}{l}\text { First line+2nd } \\
\text { first line }\end{array}$ & 9 & 3 & 33 \\
\hline
\end{tabular}

In 100 patients, 69 patients required two drug combination and 31 patients required three drugs combination to prevent seizure remission. Among 41 patients with generalised tonic clonic seizure, 11 patients were prescribed phenytoin and clonazepam tablets, 7 patients were prescribed phenytoin and clobazam tablets. In 37 patients with complex partial seizures, 6 patients were prescribed carbamazepine and levetiracetam tablets. Among 31 patients who received 3 drugs combination, 5 patients received phenytoin, sodium valproate and clonazepam tablets.

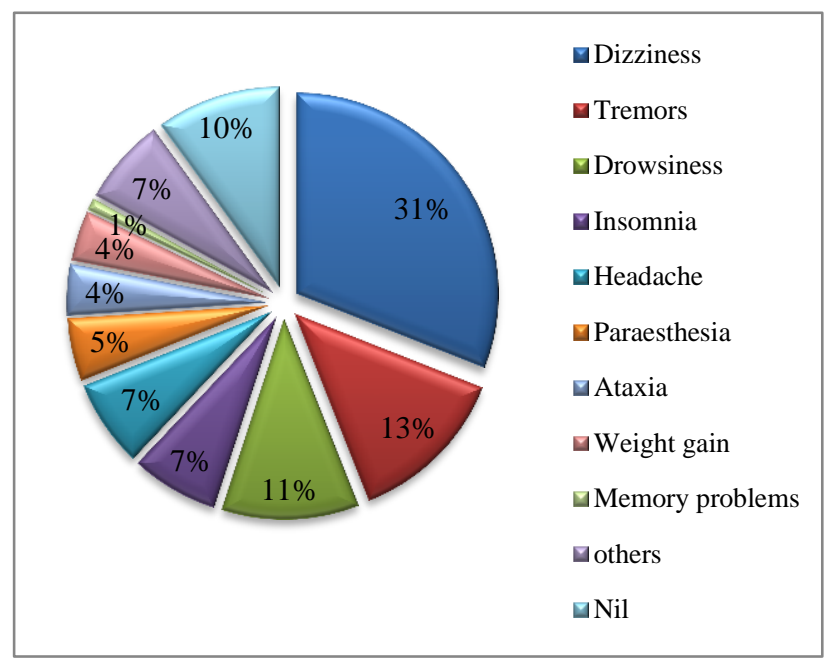

Figure 4: Adverse effects.

Most common adverse effect noted was dizziness among all patients $(31 \%)$. Other adverse effects include Tremors$13 \%$, drowsiness-11\%, insomnia-7\%, headache-7\%, paraesthesia-5\%, ataxia-4\%, weight gain-4\%, memory problems-1\% as shown in Figure 4. All adverse effects were self-reported by patients. All were mild and did not require any medical management. 


\section{DISCUSSION}

In this study, 100 eligible patients who attended Neurology outpatient department those who were started on adjuvant AEDs were observed for 4 months period for seizure remission. The percentage of seizure free patients noted to clinically correlate the effectiveness of adjuvant AEDs. Adverse effects were also noted.

Among 100 patients, $43 \%$ of patients were in the age group of 21-30 yrs. Recent Indian studies Mani et al and Banerjee et al also have similar result with increased prevalence of epilepsy in $2^{\text {nd }}$ decade. ${ }^{7,8}$ Male patients out number females which correlates with previous study Radhakrishnan et al. ${ }^{9}$ The most common type of seizure noted was generalised tonic clonic seizures. This is similar to other Indian study Joseph et al. ${ }^{10}$

Nolan et al propose that phenytoin tablet is the most commonly used first line drug . ${ }^{11}$ In our study also phenytoin tablet was prescribed to $45 \%$ patients among total 100 patients. The commonly used adjuvant AEDs were clonazepam and clobazam tablets. Among 41 patients with generalised seizures 11 patients were prescribed phenytoin and clonazepam tablets. 10 patients of them were seizure free in 4 months period. Previous study Riss et al also proposes clonazepam tablet is effective adjunct for generalised seizures. ${ }^{12} 7$ patients were prescribed phenytoin and clobazam tablets and all 7 patients were seizure free in the 4 months period. Pernea et al recommends clobazam tablets as add-on drug for both focal and generalised seizures. ${ }^{13}$

Among 37 patients with complex partial seizures, 6 patients were prescribed carbamazepine and levetiracetam tablets. Previous study also concludes levetiracetam tablet is a safe and effective adjuvant for partial seizures tablets. ${ }^{14}$ In our study among 100 patients, 31 needed 3 AEDs for seizure control. Most commonly phenytoin, sodium valproate and clonazepam tablets as prescribed to 5 patients. This is in accordance to Kwan et al which suggests that most of the patients become seizure free with two AEDs, only a few require third drug. ${ }^{15}$

Among the 100 patients, 60 patients were on first line and single adjuvant drug, in them 43 patients were seizure free (71\%). In 26 patients on two first line and one adjuvant drug, 11 were seizure free (42\%). Among 5 patients on one first line drug and 2 adjuvant drugs, 4 patients (80\%) were seizure free. 3 among 9 patients (33\%) taking two first line drugs alone were seizure free. The seizure freedom is better with adjuvant AEDs in patients not responding to first line drugs and better tolerability ${ }^{18}$ similar to Slater et al.

Of the 100 patients the common adverse effect noted was dizziness $(31 \%)$. It is the common adverse effect of all anti-epileptic drugs according to Sirven et al.${ }^{16}$ Among the 31 patients reported with dizziness 10 patients were on phenytoin tablets, 10 patients were on carbamazepine tablets and 11 patients were on sodium valproate tablets as first-line drugs. The adjuvant AEDs commonly used with these first line drugs were clonazepam and clobazam.

$13 \%$ patients presented with tremors, among them 8 were on phenytoin tablets, 3 were on sodium valproate tablets and 2 were on carbamazepine tablets as first-line drugs. They have increased propensity to cause tremors which is supported by previous studies. ${ }^{17}$ Clonazepam and clobazam tablets were the adjuvant AEDs commonly used with these first-line drugs. $11 \%$ patients presented with drowsiness, among them 5 patients were on sodium valproate tablets as first line drug. The adjuvant AEDs which were used clobazam, levetiracetam, clonazepam and lamotrigine tablets.

Though patients on adjuvant AEDs had adverse effects, it was tolerable and not amounting to stoppage of treatment. ${ }^{18}$ Long term administration of adjuvant AEDs produces lesser adverse effects and drug interactions according to Hanaya et al. ${ }^{19}$ The seizure freedom was also better in patients taking adjuvant AEDs in comparison to first line drugs alone.

\section{CONCLUSION}

Clonazepam and clobazam tablets were the commonly prescribed adjuvant AEDs. The most common adverse effect noted was dizziness. Adjuvant AEDs prevent seizure remission with fewer tolerable adverse effects. More significantly it can be proved by randomised controlled trials, comparing the efficacy and tolerability of newer adjuvant drugs with standard drugs as monotherapy in different types of seizures.

\section{ACKNOWLEDGEMENTS}

Authors would like to thank the Department of Neurology for their unconditional support. We thank the study participants and all the staff at the study centre, Govt. Stanley medical College, Chennai, Tamil Nadu, India.

\section{Funding: No funding sources}

Conflict of interest: None declared

Ethical approval: The study was approved by the Institutional Ethics Committee of Govt Stanley medical college ECR/131/Inst/TN/2013/RR-19

\section{REFERENCES}

1. Abou-Khalil BW, Gallagher MJ, Macdonald RL. Epilepsies. In: Daroff RB, Jankovic J, Mazziotta JC, Pomeroy SL, eds. Bradley's Neurology in clinical practice. 7th ed. China: Elsevier; 2016: 1563-1564.

2. Santhosh NS, Sinha S, Satishchandra P. Epilepsy: Indian Perspective. Ann Indian Acad Neurol, 2014;17(1):3-11.

3. Smith MD, Metcalf CS, Wilcox KS. Pharmacotherapy of the Epilepsies. In: Brunton LL, Hilal-Dandan R, Knollmann BC. Goodman and 
Gilman's The Pharmacological basis of therapeutics. 13th ed. New York, NY: McGraw-Hill education; 2018: 309-310.

4. Berkovic SF. Treatment with anti-epileptic drugs. Aust Fam Physician. 2005;34(12):1017-20.

5. Becerra JL, Ojeda J, Corredera E, Ruiz Gimenez J. Review of therapeutic options for adjuvant treatment of focal seizures in epilepsy: focus on lacosamide. CNS Drugs. 2011;25(1):3-16.

6. Al Za'abi M, Ahmed R, Al Asmi A, Al-Zakwani I. Utilization patterns of antiepileptic drugs among adult epileptic patients at a tertiary hospital in Oman. Int J Pharm Pract. 2013;21(2):117-22.

7. Mani KS, Rangan G, Srinivas HV, Kalyanasundaram S, Narendran S, Reddy AK. The Yelandur study: a community-based approach to epilepsy in rural South India--epidemiological aspects. Seizure. 1998;7:2818.

8. Banerjee TK, Ray BK, Das SK, Hazra A, Ghosal MK, Chaudhuri A, et al. A longitudinal study of epilepsy in Kolkata, India. Epilepsia. 2010;51(12):2384-91

9. Radhakrishnan K, Pandian JD, Santhoshkumar T, Thomas SV, Deetha TD, Sarma PS, et al. Prevalence, Knowledge, Attitude, and Practice of epilepsy in Kerala, South India. Epilepsia. 2000;41(8):1027-35.

10. Joseph N, Kumar GS, Nelliyanil M. Pattern of seizure cases in tertiary care hospitals in Karnataka state of India. Ann Indian Acad Neurol. 2013;16(3):347-51.

11. Nolan SJ, Marson AG, Weston J, Tudur Smith C. Carbamazepine versus phenytoin monotherapy for epilepsy: an individual participant data review. Cochrane Database Syst Rev. 2015;8:CD001911.
12. Riss J, Cloyd J, Gates J, Collins S. Benzodiazepines in epilepsy: pharmacology and pharmacokinetics. Acta Neurol Scand. 2008;118:69-86.

13. Pernea M, Sutcliffe AG. Clobazam and its use in epilepsy. Pediatric Reports. 2016;8(6516):34-8.

14. Hasan H. Sonmezturk and Nabil J. Azar. Levetiracetam Extended Release as Adjuvant Therapy for the Control of Partial-onset Seizures. J Cent Nerv Syst Dis. 2011;3:17-25.

15. Kwan P, Brodie MJ. Combination therapy in epilepsy: when and what to use. Drugs. 2006;66(14):1817-29.

16. Fife TD, Sirven J. Antiepileptic drugs and their impact on balance. Aging Health. 2005;1(1):147-55.

17. Zadikoff C, Munhoz RP, Asante AN, Politzer N, Wennberg R, Carlen P, et al. Movement disorders in patients taking anticonvulsants. J Neurol Neurosurg Psychiatry. 2007;78:147-51.

18. Slater J, Chung S, Huynh L, Duh MS, Gorin B, McMicken C, et al. Efficacy of antiepileptic drugs in the adjunctive treatment of refractory partial-onset seizures: Meta-analysis of pivotal trials. Epilepsy Res. 2018;143:120-9.

19. Hanaya R, Arita K. The New Antiepileptic Drugs: Their Neuropharmacology and Clinical Indications. Neurol Med Chir (Tokyo). 2016;56:205-20.

Cite this article as: Rangarajan $\mathrm{P}$, Moorthy $\mathrm{K}$, Subbiah A. Observational study on the utilization pattern of adjuvant anti-epileptics and their adverse effects. Int J Basic Clin Pharmacol 2020;9:170-4. 